\title{
Risk of a post-colonoscopy colorectal cancer in patients with type 2 diabetes: a Danish population-based cohort study
}

\author{
Frederikke Schønfeldt Troelsen (1) , ${ }^{1}$ Henrik Toft Sørensen, ${ }^{1}$ Lars Pedersen, \\ Rune Erichsen ${ }^{1,2}$
}

To cite: Troelsen FS,

Sørensen HT, Pedersen L, et al. Risk of a post-colonoscopy colorectal cancer in patients with type 2 diabetes: a Danish population-based cohort study. BMJ Open Gastro 2021;8:e000786. doi:10.1136/ bmjgast-2021-000786

- Additional supplemental material is published online only. To view, please visit the journal online (http://dx.doi. org/10.1136/bmjgast-2021000786).

Received 3 September 2021 Accepted 29 November 2021

\section{Check for updates}

C) Author(s) (or their employer(s)) 2021. Re-use permitted under CC BY-NC. No commercial re-use. See rights and permissions. Published by BMJ.

${ }^{1}$ Department of Clinical Epidemiology, Aarhus University Hospital and Aarhus University, Aarhus, Denmark

${ }^{2}$ Department of Surgery, The Regional Hospital in Randers, Randers, Denmark

Correspondence to Dr Frederikke Schønfeldt Troelsen; frtroe@clin.au.dk

\section{ABSTRACT}

Objective Prevalent type 2 diabetes (T2D) is associated with an increased risk of colorectal cancer and could impair the quality of bowel preparation for colonoscopy. This may in turn increase the risk of overlooked precancerous polyps and subsequent risk of postcolonoscopy colorectal cancer (PCCRC). We investigated whether patients with T2D are at increased risk of PCCRC compared with patients without T2D.

Design We conducted a population-based cohort study of patients with T2D and without T2D undergoing colonoscopy in Denmark (1995-2015). We investigated the risk of PCCRC by calculating $>6$ to 36 months cumulative incidence proportions (CIPs) treating death and colectomy as competing risks. Using Cox proportionalhazards regression analyses, we also computed HRs of PCCRC, comparing patients with T2D and nonT2D. According to the World Endoscopy Organization guidelines, we calculated PCCRC 3-year rates to estimate the proportions of T2D and non-T2D CRC patients experiencing PCCRC.

Results We identified 29031 patients with T2D and 333232 patients without T2D undergoing colonoscopy. We observed 250 PCCRCs among patients with T2D and 1658 PCCRCs among patients without T2D. The $>6$ to 36 months CIP after a first-time colonoscopy was $0.64 \%(95 \% \mathrm{Cl}$ $0.55 \%$ to $0.74 \%$ ) for T2D and $0.36 \%$ (95\% $\mathrm{Cl} 0.34 \%$ to $0.38 \%$ ) for patients without T2D. The HRs of PCCRC were $1.43(95 \% \mathrm{Cl} 1.21$ to 1.72$)$ after a first-time colonoscopy and $1.18(95 \% \mathrm{Cl} 0.75$ to 1.85$)$ after a second-time colonoscopy. The PCCRC 3-year rate was 7.9\% for patients with T2D and $7.4 \%$ for patients without T2D. Conclusion T2D may be associated with an increased HR of PCCRC.

\section{INTRODUCTION}

Post-colonoscopy colorectal cancer (PCCRC), a term endorsed by the World Endoscopy Organization (WEO), refers to colorectal cancers (CRCs) diagnosed after a negative colonoscopy. ${ }^{1}$ Despite the high sensitivity of colonoscopy in detecting CRC, PCCRCs may account for up to $8 \%$ of all CRCs. ${ }^{2-11}$ Previous studies have consistently reported that PCCRCs represent a high proportion of CRCs diagnosed in patients
Summary box

What is already known about this subject?

- Post-colonoscopy colorectal cancers account for up to $8 \%$ of all colorectal cancers.

- The majority is assumed to arise from colorectal lesions that were missed or insufficiently resected at initial colonoscopy.

What are the new findings?

- We found that patients with type 2 diabetes (T2D) had an increased relative risk of post-colonoscopy colorectal cancers compared with patients without T2D.

- These findings could reflect an association between T2D/metabolic syndrome and post-colonoscopy colorectal cancer development and growth or technically challenging colonoscopies and polypectomies.

How might it impact on clinical practice in the foreseeable future?

- Our findings advocate for increased awareness on colorectal lesions when conducting colonoscopies among patients with $\mathrm{T} 2 \mathrm{D}$.

with inflammatory bowel disease. ${ }^{12-17}$ Similarly, diverticular disease, prior colorectal adenomas and hereditary CRC syndromes are suggested as risk factors for a subsequent PCCRC diagnosis. ${ }^{15-17}$ This elevated PCCRC risk is presumably caused primarily by impaired colonoscopy quality, but potentially also by aggressive CRC biology leading to rapid cancer development in the interval between two colonoscopies. ${ }^{1} 16$ 18-20

For at least two reasons, type 2 diabetes (T2D) could be associated with increased risk of PCCRC, but evidence remains limited. ${ }^{17}$ First, mounting research suggests that patients with T2D are at particularly high risk of CRC. ${ }^{21-24}$ The T2D-CRC link may be due in part to presence of shared risk factors, such as obesity, sedentary lifestyle and a high-calorie diet. However, the link could also reflect T2D-associated conditions such as hyperinsulinaemia, hyperglycaemic and microbiota 
alterations promoting gastrointestinal inflammation and colorectal carcinogenesis. ${ }^{25-31}$ Second, T2D is suggested to be associated with inadequate bowel preparation for colonoscopy, possibly due to functional impairment of gastrointestinal motility. ${ }^{32-34}$ Presence of T2D could thus lead to reduced visualisation of the colonic mucosa, in turn elevating the likelihood of overlooking precancerous polyps. This subsequently could increase PCCRC risk. $^{35} 36$

Evidence regarding the impact of T2D on risk of PCCRC is needed to improve the overall colonoscopy quality and to guide clinical decision making, particularly for planning surveillance colonoscopies for patients with T2D within CRC screening programmes. The increasing need for colonoscopies in Denmark during past decades, the rapidly ageing population, and the increasing prevalence of T2D all point to the need for evidence on T2Drelated PCCRC risk. ${ }^{16} 1832$

We, therefore, conducted the present population-based cohort study to investigate the absolute and relative risk of PCCRC in patients with T2D and without T2D (aim 1) and to estimate the proportion of PCCRCs among all CRCs diagnosed in patients with T2D and without T2D (aim 2).

\section{METHODS}

\section{Setting}

The study setting was the universal, tax-funded Danish healthcare system provided by the National Health Service. ${ }^{37}$ We used existing Danish registries to conduct our population-based cohort study within the period 1 January 1995 to 31 December 2015. Individual-level data were linked using the unique 10-digit civil registration number issued to each Danish resident at birth or on emigration by the Danish Civil Registration System (CRS) ${ }^{38}{ }^{39}$ In addition, CRS data allowed for monitoring of deaths and emigration from Denmark. The study was reported to the Danish Data Protection Agency by Aarhus University (Record no. 2016-051-000001/1671).

\section{Aim 1: risk of a PCCRC}

\section{Colonoscopy cohort}

We included all individuals with at least one colonoscopy performed during the study period as recorded in the Danish National Patient Registry (DNPR). The DNPR contains medical records on all in-hospital stays since 1977 and, since 1995, records on all hospital outpatient visits and contacts with emergency rooms. ${ }^{40}$ Data include civil registration number, dates of hospital admission and discharge, surgical procedures (including colonoscopies), and up to 20 discharge diagnoses coded according to the International Classification of Diseases (ICD), 8th Revision until the end of 1993 and 10th Revision (ICD10) thereafter. Since 1995, reporting of colonoscopies performed during outpatient visits has been mandatory. The quality of coding for colonoscopies in the DNPR is well documented, also before 1995 for colonoscopies conducted during in-hospital stays. ${ }^{16}$ Of note, the majority of all Danish colonoscopies are performed at public hospitals. Private endoscopy clinics conduct only a small proportion of colonoscopies, and even at these clinics, experts perform the exams.

For all patients included in the colonoscopy cohort, data from the DNPR and the Danish National Health Service Prescription Database (DNHSPD) were used to categorise them into patients with T2D and without T2D. The DNHSPD contains data on all drug prescriptions redeemed in Danish community pharmacies since $2004 .{ }^{41}$ According to a previously validated algorithm, we defined patients with T2D as individuals who redeemed a prescription for a glucose-lowering drug, and/or received a hospital discharge or outpatient diagnosis of T2D before or within 90 days after their first-time colonoscopy. ${ }^{42}$ In line with previous research, we considered type 1 diabetes as a first-time diagnosis of diabetes recorded in the DNPR before age 30 or at least one redeemed prescription for a glucose-lowering drug recorded in the DNHSPD before age 30 in our main analysis. ${ }^{42}$ The remaining patients with diabetes mellitus were considered to represent patients with T2D.

In line with our previous study on risk of PCCRC among patients with inflammatory bowel disease, we defined the initial colonoscopy recorded in the DNPR as colonoscopy $\# 1{ }^{43}$ The first subsequent colonoscopy recorded more than 6 months after colonoscopy \#1 was considered colonoscopy \#2. In the same manner, we required colonoscopies \#3, \#4, and \#5 to be recorded more than 6 months after colonoscopies number \#2, \#3, and \#4, respectively. Patients with T2D and without T2D with a record of CRC, total colectomy or diagnosis of type 1 diabetes and/or inflammatory bowel disease before the date of their first-time colonoscopy were excluded. For patients with multiple colonoscopies recorded in the DNPR, we reassessed T2D status and exclusion criteria for each colonoscopy separately, permitting patients without T2D to join the T2D cohort if they received a T2D diagnosis or redeemed a prescription for a glucose-lowering drug within 90 days after a subsequent follow-up colonoscopy.

\section{Pos-tcolonoscopy colorectal cancers}

We obtained data from the Danish Cancer Registry (DCR) on incident CRCs recorded after the first-time colonoscopy. The DCR contains records on all incident malignant neoplasms diagnosed in Denmark since 1943, including diagnosis date, tumour location and tumour stage at diagnosis. ${ }^{44}$ Cancers are currently coded according to ICD-10. We categorised CRCs by stage at diagnosis into: localised, regional, metastatic and unknown in accordance with the Tumor, Node, and Metastasis (TNM) classification system. In line with the WEO, we defined PCCRC as CRC diagnosed within $>6$ to 36 months following a colonoscopy in which no cancer was detected. ${ }^{1}$

\section{Comorbidities}

Data on potential cofounders (ie, factors that directly or indirectly through associated lifestyle factors could be associated 
with both T2D and CRC) were collected from the DNPR and included atrial fibrillation/flutter, cardiovascular diseases including hypertension, chronic obstructive pulmonary disease, renal disease, alcohol-related diseases, diverticular diseases, obesity and familial hereditary CRC syndromes recorded since 1977.

\section{Aim 2: PCCRC 3-year rates CRC cohort}

We used the DNPR and the DCR to identify all CRCs recorded within 0-36 months after a preceding colonoscopy. PCCRCs were defined as CRCs occurring $>6$ to 36 months after the previous colonoscopy. Colonoscopies that failed to detect a later-diagnosed CRC were defined as 'false-negative'. We defined CRCs diagnosed within 6 months after a preceding colonoscopy as detected CRCs (dCRCs). The colonoscopies during which dCRCs were detected were denoted as 'true-positive'. For all CRCs, we searched the DNPR and DNHSPD to obtain information on potential presence of T2D recorded before or within 90 days after a true-positive (for dCRCs) or false-negative colonoscopy (for PCCRCs). If a PCCRC patient had a false-negative followed by a true-positive colonoscopy, their T2D status was assessed around the time of the false-negative colonoscopy.

\section{Statistical analyses}

Aim 1: risk of PCCRC

We followed patients with T2D and without T2D from $>6$ months after the date of their first-time colonoscopy until first occurrence of PCCRC, death, total colectomy, emigration or 36 months. Patients who received a diagnosis of dCRC, underwent a total colectomy, died or emigrated within 6 months after the colonoscopy were excluded from this part of our study. For patients with multiple colonoscopies, we applied the same methodology for each colonoscopy individually. As an absolute risk measure, we computed $>6$ to 36 month cumulative incidence proportions (CIPs) of PCCRC with associated $95 \%$ CIs in patients with T2D and without T2D after first-time and subsequently performed colonoscopies (up to five colonoscopies). Death and total colectomy were treated as competing risks of PCCRC. The CIPs were modelled using the 'stcompet' command for Stata statistical software package introduced in 2004 by Coviello and Boggess. ${ }^{45}$ This user-written command calculates non-parametric estimates of the cause-specific CIPs, accounting for the fact that it is impossible to experience the event (ie, PCCRC) if a competing event is occurring before (ie, death or total colectomy). We stratified CIPs by sex, age at colonoscopy, and time since previous colonoscopy. In addition, we used Cox proportional-hazards regression analyses to compute crude and HRs and associated 95\% CIs as a measure of relative risks. The adjusted model included sex, age at colonoscopy, year of colonoscopy and presence of the comorbidities mentioned above recorded before or on the date of colonoscopy (first-time and subsequent). Patients without T2D served as the reference group. Time elapsed since first-time colonoscopy was considered the underlying time scale. We stratified HRs by sex, age at colonoscopy, diabetes medication before colonoscopy and cancer stage at diagnosis.

\section{Aim 2: PCCRC 3-year rates}

According to the WEO guidelines, we calculated PCCRC 3-year rates in patients with T2D and without T2D by dividing the number of false-negative colonoscopies by the total number of true-positive and false-negative colonoscopies. ${ }^{1}$ For individuals who underwent multiple colonoscopies, only the first false-negative and the first true-positive colonoscopy were included in the PCCRC 3-year rate calculation. We stratified PCCRC 3-year rates by sex, age at colonoscopy and year of colonoscopy among patients with T2D and without T2D.

\section{Sensitivity analyses}

Due to varying data availability over the study period, we identified patients with T2D using both ICD codes in the DNPR during 1977-2013 and prescription redemptions recorded in the DNHSPD during 20042013. We evaluated the impact of our identification method by conducting a sensitivity analysis restricting the study cohort to patients who underwent colonoscopies during 2005-2012 (allowing 1 year of prescription records prior to colonoscopies performed in 2005). Additionally, this restricted analysis evaluated the potential impact of left truncation for colonoscopies performed during outpatient visits before 1995 without records captured in the DNPR.

Furthermore, we assessed the $>6$ to 36 months cut-off for the PCCRC definition set by the WEO by extending the PCCRC definition to CRCs diagnosed within $>6$ to 60 months after a preceding colonoscopy. To permit at least 60 months of postcolonoscopy follow-up, we restricted this analysis to colonoscopies performed during 1995-2010. This allowed us to calculate CIPs and HRs as described above. PCCRC 5-year rates were calculated including colonoscopies performed during 1995-2015, but with the extended definitions.

Finally, hyperinsulinaemia may be promitogenic, which in turn could increase the risk of PCCRC in patients with T2D. The hyperinsulinaemia is usually followed by insulin supplementation, and we, therefore, evaluated the impact of insulin treatment comparing the risk of PCCRC in patients with T2D needing insulin versus those not needing insulin. Data management and statistical analyses were performed using the Stata statistical software package V.15.1 (StataCorp). All diagnosis and procedure codes are listed in online supplemental table 1). 


\section{RESULTS}

Aim 1: colonoscopy cohort characteristics

We identified 29031 patients with T2D and 333232 patients with without T2D who underwent a first-time colonoscopy during 1995-2012 (table 1).

In total, $3402(1 \%)$ patients without T2D were diagnosed with T2D or redeemed a prescription for a glucoselowering drug prior to a subsequent colonoscopy and then joined the T2D cohort.

Compared with patients without T2D, patients with T2D were more likely to be male $(52.8 \%$ vs $44.0 \%)$, older at first-time colonoscopy (median age at colonoscopy: 69.0 vs 61.0 years), and to have a higher burden of chronic obstructive pulmonary disease, atrial fibrillation/ flutter, cardiovascular diseases including hypertension, renal diseases, alcohol-related diagnoses, obesity and diverticular diseases. The proportion of cardiovascular diseases was particularly elevated for patients with T2D (56.4\% vs $20.9 \%)$. Remaining characteristics were quite equally distributed among patients with and without T2D (table 1).

\section{Cumulative incidence proportions of PCCRC}

We observed 160 cases of T2D-related PCCRC recorded after a first-time colonoscopy, yielding the $>6$ to 36 months CIP of $0.64 \% \quad(95 \%$ CI $0.55 \%$ to $0.74 \%$ ) (figure 1). In the group of patients without T2D, 1099 cases of PCCRC were observed, yielding a CIP of 0.36 (95\% CI 0.34 to 0.38 ) (figure 2). Stratification by age at first-time colonoscopy revealed a slightly increased risk of PCCRC with increasing age (figures 1 and 2). Stratification by sex and time since colonoscopy yielded no material differences in risk of PCCRC between patients with and without T2D (figures 1 and 2). The $>6$ to 36 months CIPs after subsequent colonoscopies were comparably low in both groups. Estimates were less than $1 \%$ for virtually all follow-up colonoscopies in T2D as well as patients without T2D (figures 1 and 2). The small number of PCCRCs recorded after colonoscopies \#4 and \#5 impaired possibilities for stratifications (figures 1 and 2).

\section{HRs of PCCRC}

Table 2 shows crude and adjusted HRs of PCCRC in patients with T2D compared with patients without T2D.

Patients with T2D had an elevated HR of PCCRC after colonoscopy \#1 (HR 1.44, 95\% CI 1.21 to 1.72 ) and \#2 (HR $1.18,95 \%$ CI 0.75 to 1.85 ). Stratification by sex and age at colonoscopy revealed no clear patterns while stratification by cancer stage at diagnosis showed a particularly elevated risk of metastatic cancers after the first colonoscopy (HR 1.73, 95\% CI 1.22 to 2.47). Prescriptions for insulin recorded before colonoscopy \#1 and \#2 were associated with a particularly elevated HR of PCCRC. Likewise, prescriptions for metformin were associated with an increased HR after colonoscopy \#1 and \#2 while
Table 1 Characteristics of patients undergoing at least one colonoscopy* in Denmark during 1995-2012, by presence/ absence of type 2 diabetes (T2D)†

\begin{tabular}{lll} 
& $\begin{array}{l}\text { Patients with } \\
\text { T2D, n (\%) }\end{array}$ & $\begin{array}{l}\text { Patients with } \\
\text { outT2D, n (\%) }\end{array}$ \\
\hline Total & $29031(100)$ & $333232(100)$ \\
\hline Female & $13474(46.4)$ & $186602(56.0)$ \\
\hline Male & $15557(53.6)$ & $146630(44.0)$
\end{tabular}

Age at first-time colonoscopy, years

\begin{tabular}{|c|c|c|}
\hline $\begin{array}{l}\text { Median age } \\
\text { at first-time } \\
\text { colonoscopy (IQR) }\end{array}$ & $69.0(61.0-76.5)$ & $61.0(49.0-71.8)$ \\
\hline $0-59$ & $6537(22.5)$ & $158339(47.5)$ \\
\hline $60-69$ & $8906(30.7)$ & $78846(23.7)$ \\
\hline $70+$ & $13588(46.8)$ & $96047(28.8)$ \\
\hline \multicolumn{3}{|c|}{ ear of first-time colonoscopy } \\
\hline 1995-2000 & $2366(8.2)$ & $54667(16.4)$ \\
\hline 2001-2006 & $8137(28.0)$ & $113059(33.9)$ \\
\hline 2007-2012 & $18528(63.8)$ & 165506 (49.7) \\
\hline \multicolumn{3}{|c|}{ ype of admission for colonoscopy } \\
\hline Inpatient unit & $11002(37.9)$ & $96036(28.8)$ \\
\hline Outpatient clinic & $18029(62.1)$ & 237196 (71.2) \\
\hline
\end{tabular}

Region of first-time colonoscopy

\begin{tabular}{|c|c|c|}
\hline Capital & 6741 (23.2) & $61853(18.6)$ \\
\hline Zealand & 4110 (14.2) & 41091 (12.3) \\
\hline Southern & 7935 (27.3) & $92580(27.8)$ \\
\hline Central & $6846(23.6)$ & $91630(27.5)$ \\
\hline Northern & 3132 (10.8) & 38993 (11.7) \\
\hline Unknown & $267(0.9)$ & $7085(2.1)$ \\
\hline \multicolumn{3}{|l|}{ Comorbidities $^{\ddagger}$} \\
\hline $\begin{array}{l}\text { Chronic } \\
\text { obstructive } \\
\text { pulmonary } \\
\text { disease }\end{array}$ & 2837 (9.8) & $14637(4.4)$ \\
\hline $\begin{array}{l}\text { Atrial fibrillation/ } \\
\text { flutter }\end{array}$ & 3977 (13.7) & $16944(5.1)$ \\
\hline $\begin{array}{l}\text { Cardiovascular } \\
\text { diseases }\end{array}$ & 16749 (57.9) & 69713 (20.9) \\
\hline Renal disease & $1836(6.3)$ & 5997 (1.8) \\
\hline $\begin{array}{l}\text { Alcohol-related } \\
\text { diagnoses }\end{array}$ & $1842(6.3)$ & 9953 (3.0) \\
\hline Obesity & 4159 (14.3) & 7599 (2.3) \\
\hline $\begin{array}{l}\text { Diverticular } \\
\text { disease }\end{array}$ & $3504(12.1)$ & 33048 (9.9) \\
\hline $\begin{array}{l}\text { Familial hereditary } \\
\text { colorectal cancer } \\
\text { syndromes }\end{array}$ & $108(0.4)$ & 3624 (1.1) \\
\hline
\end{tabular}

Year of first-time T2D diagnosis/prescription for a glucoselowering drug

\begin{tabular}{llll}
$1977-1986$ & $1745(6.0)$ & N/A & \\
$1987-1996$ & $4511(15.5)$ & N/A & \\
$1997-2006$ & $15852(54.6)$ & N/A & \\
\hline & & & Continued
\end{tabular}




\begin{tabular}{lll}
\hline Table 1 Continued & \\
\hline & $\begin{array}{l}\text { Patients with } \\
\text { T2D, n (\%) }\end{array}$ & $\begin{array}{l}\text { Patients with } \\
\text { outT2D, n (\%) }\end{array}$ \\
\hline $2007-2013$ & $6923(23.8)$ & N/A \\
\hline
\end{tabular}

Numbers below 5 are marked with $<5$ to ensure anonymity according to Danish legislation.

*Patients with a diagnosis of colorectal cancer or inflammatory bowel disease and patients who underwent a total colectomy before their first-time colonoscopy are not included.

†Diagnosis of T2D recorded in the Danish National Patient

Registry before or within 90 days after a first-time colonoscopy and/or at least one redeemed prescription for a glucoselowering drug recorded in the Danish National Health Service Prescription Database before or within 90 days after a first-time colonoscopy. Patients with a first-time diagnosis of diabetes in the Danish National Patient Registry or at least one redeemed prescription for a glucose-lowering drug recorded in the Danish National Health Service Prescription Database before age 30 were considered as having type 1 diabetes and were not included.

$\ddagger$ Recorded before the date of first-time colonoscopy in the Danish National Patient Registry.

prescriptions for sulfonylureas were associated with an increased HR after colonoscopy \#1.

\section{Aim 2: PCCRC 3-year rates}

We identified 250 false-negative and 2938 true-positive colonoscopies in patients with T2D, yielding a PCCRC 3-year rate of $7.9 \%$ for patients with T2D (table 3). Among patients without T2D, we observed 1658 falsenegative and 20594 true-positive colonoscopies, yielding a PCCRC 3-year rate of 7.4\% (table 3). The PCCRC 3-year rates were elevated among women for both patients with and without T2D.

\section{Sensitivity analyses}

Restriction to a cohort comprising colonoscopies performed during 2005-2012 revealed the same pattern as observed in our main analysis. However, we found a more pronounced increase in the HRs of PCCRC comparing patients with T2D with patients without T2D than observed in our main analysis. Estimates of $>6$ to 36 months CIPs were less than $1 \%$ for both patients with and without T2D (online supplemental table 2). Comparing patients with T2D with patients without T2D, the HRs of PCCRC were 1.57 (95\% CI 1.28 to 1.93) after colonoscopy \#1 and 1.74 (95\% CI 0.95 to 3.16) after colonoscopy \#2 (online supplemental table 3). The PCCRC 3-year rate was slightly higher in patients with T2D than in patients without T2D (7.0\% vs $5.4 \%$ ) (online supplemental table 4). Rates for both groups were slightly decreased compared with our main analysis.

The sensitivity analysis evaluating the PCCRC cut-off set by the WEO showed low CIPs of PCCRC for patients with and without T2D (online supplemental table 5) and slightly elevated HRs of PCCRC after colonoscopy \#1 and \#2 (online supplemental table 6). Not surprisingly, expanding the PCCRC definition resulted in increased PCCRC 5-year rates for both patients with and without
T2D, but without material differences between the two groups (9.9\% vs $10.2 \%$ ) (online supplemental table 7 ). Our analysis investigating the impact of potential hyperinsulinaemia showed that patients with T2D requiring insulin had a higher risk of PCCRC after a first and second-time colonoscopy (online supplemental table 8).

\section{DISCUSSION}

In this population-based cohort study including virtually all patients undergoing colonoscopy in Denmark during 1995-2015, we observed a 44\% increased HR of PCCRC after a first-time colonoscopy when comparing patients with T2D with patients without T2Ds. However, the corresponding CIPs after first-time and subsequent colonoscopies were below $1 \%$ for patients with as well as without T2D. The proportion of CRC diagnoses that could be categorised as PCCRC was only marginally elevated for patients with T2D.

Several previous studies have reported an increased risk of CRC in patients with T2D. ${ }^{21-24}{ }^{46-51}$ However, only limited knowledge on the impact of T2D on PCCRC risk exists. ${ }^{17}$ In line with our findings, a Swedish study by Forsberg et al suggested a slightly increased relative risk of PCCRC in diabetic patients $(1.13,95 \%$ CI 0.99 to 1.30). Overall, most PCCRCs are thought to arise from overlooked lesions, while the proportion of PCCRC appearing as rapidly growing lesions is probably low. ${ }^{1}$ Although our study was unable to address the reason for the increased HRs, we speculate that presence of T2D might be associated with an elevated risk of inadequate bowel preparation for colonoscopy, in turn impairing the detection of both small and large adenomas and even cancers. Our finding of decreasing HRs with increasing numbers of colonoscopies supports for the hypothesis as repeated colonoscopies would lower the number of potential missed or incompletely resected polyps with the potential to progress to invasive CRC. The elevated HR of metastatic PCCRC after a first-time colonoscopy indicates that missed precursors could be the predominant origin for T2D-related PCCRC as these polyps or even cancers would have a prolonged time to diagnosis and thereby a higher likelihood of progression to advance stage disease. ${ }^{335253}$ Concurrently, it is necessary to consider that the effects of long-standing T2D might affect the molecular pathways driving CRC initiation. The progressive impairment of insulin sensitivity among patients with T2D could lead to chronic compensatory hyperinsulinaemia. ${ }^{54-56}$ Endogenic as well as exogenic insulin may promote colorectal carcinogenesis through enhanced stimulation of the insulin-like growth factor-1 receptor, in turn increasing cell proliferation and prolonging their survival. ${ }^{25}$ Accordingly, our analysis investigating the potential impact of hyperinsulinaemia showed that patients with T2D requiring insulin supplementation may have a higher risk of PCCRC than those not requiring insulin. In addition, patients with T2D with prescriptions for insulin had a particularly increased risk 


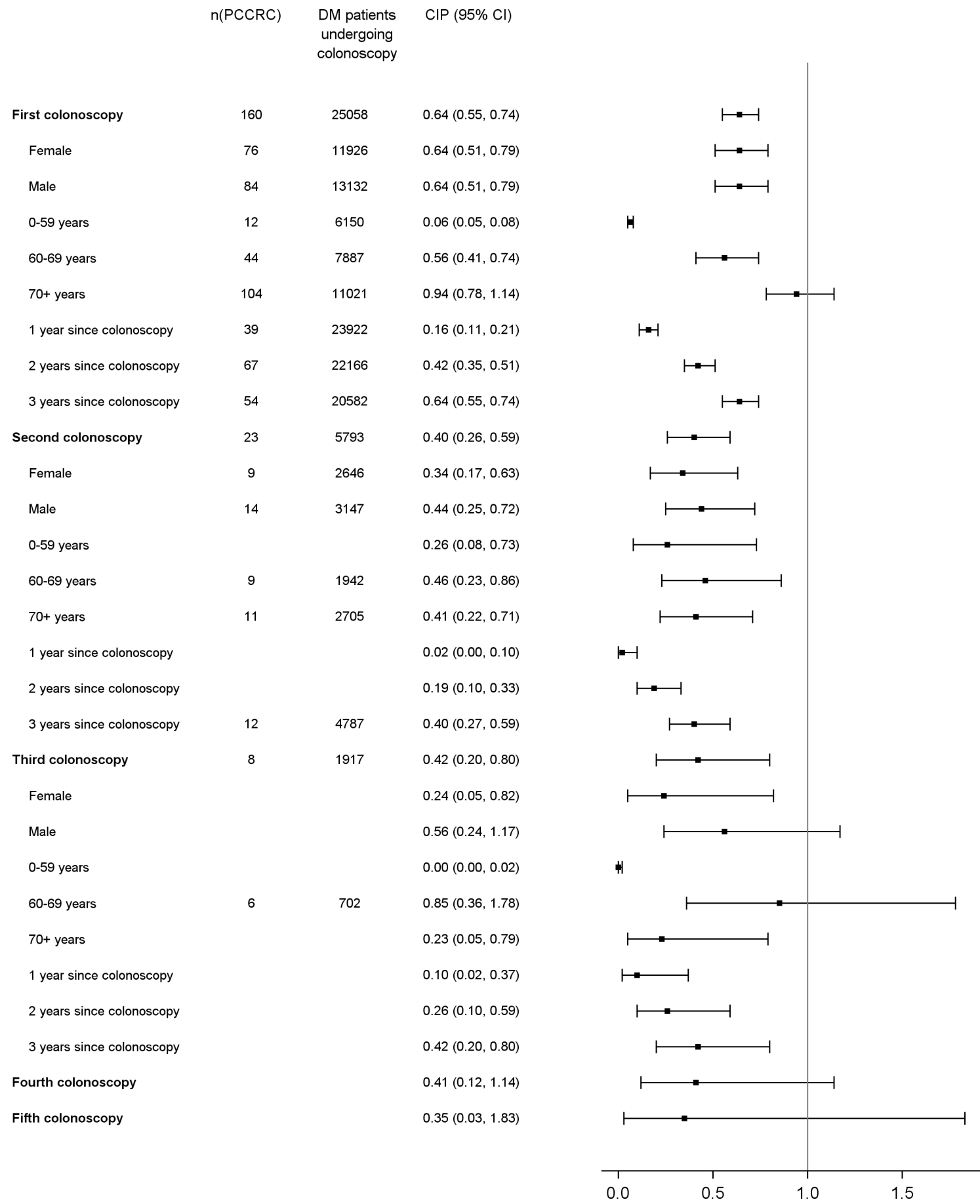

Figure 1 Cumulative incidence proportions (CIPs) in percentages with associated $95 \%$ Cls of postcolonoscopy colorectal cancers (PCCRCs) ${ }^{1}$ among patients with type 2 diabetes (T2D) ${ }^{2}$ who underwent colonoscopy in Denmark during 1995-2012 . Death and total colectomy ${ }^{4}$ are treated as competing risks. PCCRCs were diagnosed in Denmark during 1995-2015. Numbers below 5 are not included to ensure anonymity according to Danish legislation. ${ }^{1}$ Colorectal cancer diagnosed within $>6$ to 36 months after a negative colonoscopy. ${ }^{2}$ Diagnosis of T2D recorded in the Danish National Patient Registry before or within 90 days after a first-time colonoscopy and/or at least one redeemed prescription for a glucose-lowering drug recorded in the Danish National Health Service Prescription Database before or within 90 days after the first-time colonoscopy. Patients with diabetes diagnoses and prescriptions recorded before age 30 not included as these were considered to represent patients with type 1 diabetes. ${ }^{3}$ Allowing 36 months of follow-up after colonoscopies performed in 2012. ${ }^{4}$ Date of total colectomy recorded in the Danish National Patient Registry plus 90 days. DM, diabetes mellitus.

of PCCRC compared with patients with non-T2D. Use of insulin among patients with T2D may, therefore, serve as a 'red flag' that could indicate a potential increased risk of PCCRC. These findings could, however, also be explained by other factors such as differences in T2D disease severity and should be interpreted with caution. In addition, inflammation is a crucial component of T2Dinduced organ injury and long-standing inflammation 


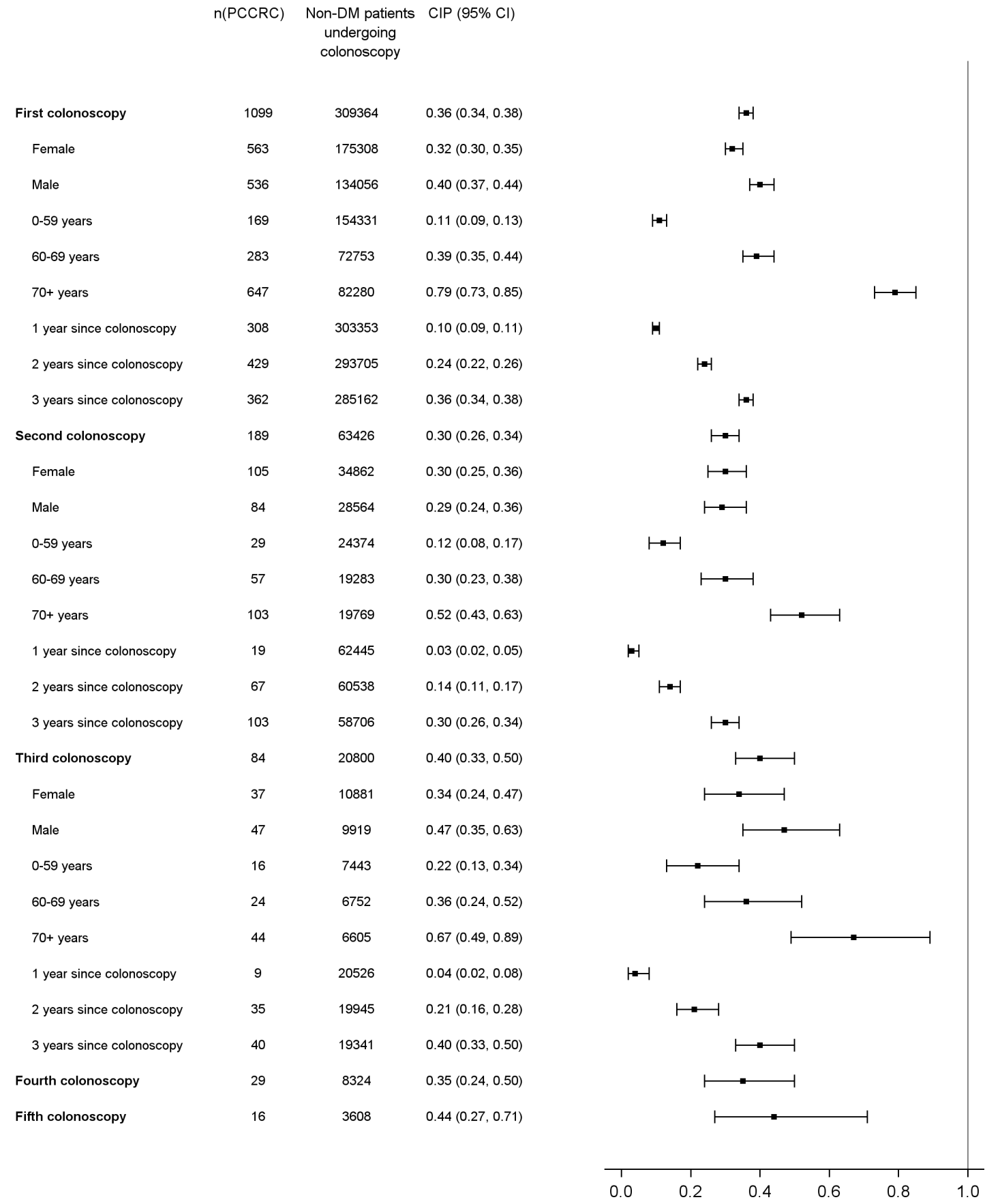

Figure 2 Cumulative incidence proportions (CIPs) in percentages with associated 95\% Cls of postcolonoscopy colorectal cancers (PCCRCs) ${ }^{1}$ among patients without type 2 diabetes (T2D) ${ }^{2}$ who underwent colonoscopy in Denmark during 1995$2012^{3}$. Death and total colectomy ${ }^{4}$ are treated as competing risks. PCCRCs were diagnosed in Denmark during $1995-2015$. ${ }^{1}$ Colorectal cancer diagnosed within $>6$ to 36 months after a negative colonoscopy. ${ }^{2}$ Diagnosis of T2D recorded in the Danish National Patient Registry before or within 90 days after first-time colonoscopy and/or at least one redeemed prescription for a glucose-lowering drug recorded in the Danish National Health Service Prescription Database before or within 90 days after the first-time colonoscopy. ${ }^{3}$ Allowing 36 months of follow-up after colonoscopies performed in $2012 .{ }^{4}$ Date of total colectomy recorded in the Danish National Patient Registry plus 90 days. DM, diabetes mellitus.

may enhance CRC development. ${ }^{24}$ Accordingly, inflammation is suggested as one reason for increased CRC risk in patients with inflammatory bowel disease. ${ }^{57-61} \mathrm{~A}$ different or particularly aggressive CRC biology could therefore also play an important role for PCCRC pathogenesis in patients with T2D. We consider, however, it beyond the scope of this study to investigate the exact impact of T2D on molecular PCCRC features. Future research is needed to provide the necessary answers.

The strengths of our study include its population-based design, its setting within a universal, tax-funded healthcare system, and use of high-quality, prospectively collected data on colonoscopies and other diagnoses. ${ }^{37} 4062$ The virtually complete follow-up for all patients undergoing 
Table 2 Crude and adjusted HRs and associated 95\% Cls of PCCRC* after one, two, three, four and five colonoscopies, comparing patients with type 2 diabetes (T2D)† with non-T2D

\section{Crude HR (95\% Cl)}

\begin{tabular}{|c|c|c|}
\hline First colonoscopy & 1.89 (1.60 to 2.24$)$ & 1.44 (1.21 to 1.72$)$ \\
\hline \multicolumn{3}{|l|}{ Sex } \\
\hline Female & 2.07 (1.63 to 2.63$)$ & 1.52 (1.18 to 1.95$)$ \\
\hline Male & 1.69 (1.34 to 2.13$)$ & 1.38 (1.08 to 1.76$)$ \\
\hline \multicolumn{3}{|l|}{ Age at colonoscopy } \\
\hline $0-59$ & 1.83 (1.02 to 3.28$)$ & 1.77 (0.95 to 3.30$)$ \\
\hline $60-69$ & 1.49 (1.08 to 2.04$)$ & 1.80 (1.29 to 2.52$)$ \\
\hline $70+$ & 1.25 (1.02 to 1.54$)$ & 1.29 (1.04 to 1.60$)$ \\
\hline \multicolumn{3}{|l|}{ Medication§ } \\
\hline Insulin & 2.42 (1.81 to 3.24$)$ & 2.15 (1.58 to 2.92 ) \\
\hline Metformin & 1.64 (1.30 to 2.06$)$ & 1.46 (1.14 to 1.87$)$ \\
\hline Sulfonylureas & 1.98 (1.51 to 2.60$)$ & 1.53 (1.15 to 2.03$)$ \\
\hline Other antidiabetic drugs & N/A & N/A \\
\hline \multicolumn{3}{|l|}{ PCCRC stage at diagnosis } \\
\hline Localised & 1.52 (1.14 to 2.03$)$ & 1.21 (0.89 to 1.64$)$ \\
\hline Regional & 1.47 (0.98 to 2.21$)$ & $1.22(0.80$ to 1.87$)$ \\
\hline Metastatic & 2.24 (1.60 to 3.13$)$ & 1.73 (1.22 to 2.47$)$ \\
\hline Unknown & 2.81 (2.01 to 3.92 ) & 1.78 (1.25 to 2.53$)$ \\
\hline Second colonoscopy & 1.45 (0.94 to 2.23$)$ & 1.18 (0.75 to 1.85$)$ \\
\hline \multicolumn{3}{|l|}{ Sex } \\
\hline Female & 1.20 (0.61 to 2.38$)$ & 0.95 (0.47 to 1.92$)$ \\
\hline Male & 1.66 (0.94 to 2.93$)$ & 1.44 (0.80 to 2.60$)$ \\
\hline \multicolumn{3}{|l|}{ Age at colonoscopy } \\
\hline $0-59$ & 2.44 (0.74 to 8.03$)$ & 3.12 (0.91 to 10.69$)$ \\
\hline $60-69$ & 1.69 (0.83 to 3.41$)$ & 1.55 (0.74 to 3.24$)$ \\
\hline $70+$ & 0.85 (0.4 to 1.58$)$ & 0.85 (0.45 to 1.62$)$ \\
\hline \multicolumn{3}{|l|}{ Medication§ } \\
\hline Insulin & 1.84 (0.90 to 3.74$)$ & 1.63 (0.79 to 3.39$)$ \\
\hline Metformin & 1.69 (1.00 to 2.86$)$ & 1.47 (0.85 to 2.55$)$ \\
\hline Sulfonylureas & 1.19 (0.56 to 2.54$)$ & 0.95 (0.44 to 2.06$)$ \\
\hline Other antidiabetic drugs & N/A & N/A \\
\hline \multicolumn{3}{|l|}{ PCCRC stage at diagnosis } \\
\hline Localised & 1.08 (0.50 to 2.35$)$ & 1.02 (0.46 to 2.26$)$ \\
\hline Regional & 1.51 (0.53 to 4.27$)$ & 1.24 (0.41 to 3.71$)$ \\
\hline Metastatic & 0.95 (0.29 to 3.09$)$ & 0.79 (0.23 to 2.68$)$ \\
\hline Unknown & 2.49 (1.21 to 5.11$)$ & 1.62 (0.77 to 3.42$)$ \\
\hline Third colonoscopy ${ }^{\star *}$ & 1.12 (0.54 to 2.31$)$ & 0.78 (0.37 to 1.67$)$ \\
\hline \multicolumn{3}{|l|}{ Sex } \\
\hline Female & 0.75 (0.18 to 3.13$)$ & 0.68 (0.16 to 2.93$)$ \\
\hline Male & 1.27 (0.55 to 2.99$)$ & 0.83 (0.34 to 2.) \\
\hline \multicolumn{3}{|l|}{ Age at colonoscopy } \\
\hline $0-59$ & N/A & N/A \\
\hline $60-69$ & 2.59 (1.06 to 6.34$)$ & $1.92(0.71$ to 5.20$)$ \\
\hline $70+$ & 0.37 (0.09 to 1.52$)$ & 0.32 (0.07 to 1.34$)$ \\
\hline
\end{tabular}

Continued 
Table 2 Continued

\begin{tabular}{lll}
\hline & Crude HR (95\% Cl) & Adjusted HR (95\% Cl) \\
\hline Medication§ & & $0.66(0.16$ to 2.81$)$ \\
\hline Insulin & $1.02(0.25$ to 4.15$)$ & $0.99(0.38$ to 2.56$)$ \\
\hline Metformin & $1.31(0.53$ to 3.23$)$ & $0.54(0.13$ to 2.25$)$ \\
\hline Sulfonylureas & $0.74(0.18$ to 2.98$)$ & $\mathrm{N} / \mathrm{A}$ \\
\hline Other antidiabetic drugs & $\mathrm{N} / \mathrm{A}$ & $0.51(0.12$ to 2.14$)$ \\
\hline PCCRC stage at diagnosis & & $1.23(0.15$ to 10.29$)$ \\
\hline Localised & $0.54(0.13$ to 2.23$)$ & $0.61(0.13$ to 2.80$)$ \\
\hline Regional & $1.46(0.18$ to 11.71$)$ & $1.62(0.43$ to 6.02$)$ \\
\hline Metastatic & $1.20(0.28$ to 5.15$)$ & $1.18(0.35$ to 3.98$)$ \\
\hline Unknown & $2.72(0.77$ to 9.56$)$ & $0.81(0.10$ to 6.41$)$
\end{tabular}

Denmark, 1995-2015.

${ }^{*}$ Colorectal cancer diagnosed within $>6$ to 36 months after a negative colonoscopy.

†Diagnosis of T2D recorded in the Danish National Patient Registry before or within 90 days after a first-time colonoscopy and/or at least one redeemed prescription for a glucose-lowering drug recorded in the Danish National Health Service Prescription Database before or within 90 days a first-time colonoscopy. Patients with diabetes diagnoses and prescriptions recorded before age 30 not included as these were considered to represent patients with type 1 diabetes.

$\ddagger$ Adjusted for age group, sex, year of colonoscopy and presence of chronic obstructive pulmonary disease, atrial fibrillation/flutter, cardiovascular diseases, renal diseases, alcohol-related diseases diverticular diseases, obesity and familial hereditary colorectal cancer syndromes.

§Comparing patients with T2D with prescriptions for the given medication before the relevant colonoscopy with patients with non-T2D.

Patients T2D are allowed to be included in multiple medication groups.

१The first subsequent colonoscopy recorded more than 6 months after the first-time colonoscopy.

${ }^{*}$ The first colonoscopy recorded more than 6 months after the second colonoscopy.

$\dagger \dagger$ The first colonoscopy recorded more than 6 months after the third colonoscopy.

抽 first colonoscopy recorded more than 6 months after the fourth colonoscopy.

PCCRC, postcolonoscopy colorectal cancer; T2D, type 2 diabetes.

colonoscopy in Denmark allowed us to calculate PCCRC 3-year rates, as suggested by the WEO, as well as the absolute risk of PCCRC after colonoscopy.

However, our study also has limitations. First, due to differing data availability over the study period, the cohort of patients without T2D may have included patients with T2D treated solely by general practitioners during 1995-2003. Accordingly, our sensitivity analysis restricted to colonoscopies performed during 2005-2012 indicated that our main analysis might have underestimated the HR of PCCRC in patients with T2D. This is most likely due to misclassification of patients considered as patients without T2D in our study who were actually treated for T2D by their general practitioner. In addition, the PCCRC 3-year rates for T2D as well as patients without T2D were lower than in our main analysis. This may be explained by the overall decreasing trend for PCCRC 3-year rates in Denmark (ranging from 22.1\% in 2001 to $7.7 \%$ in 2012 ) as previously described by Pedersen et al. ${ }^{15}$ Although the rates were generally lower, we observed an increased difference in the PCCRC 3-year rates among patients with and without T2D with PCCRCs accounting for a higher proportion of all CRCs diagnosed in patients with T2D. The elevation in PCCRC 3-year rates for T2D patients can likely be explained by the misclassification bias described above.

Second, the DNPR lacks detailed data on colonoscopy quality (including completeness, quality of bowel preparation, and withdrawal time), on polypectomies, and on the indication for colonoscopy. Thus, we were unable to directly explore causes of PCCRC in patients with T2D. A detailed case review investigating the causes of PCCRC in patients with T2D would be needed. Such knowledge would have profound implications for patients, endoscopists, and those writing surveillance guidelines. Of note, the Danish CRC screening programme was introduced nationwide in March 2014. ${ }^{63}$ Therefore, most patients included in the colonoscopy cohort underwent colonoscopy due to symptoms of CRC or other gastrointestinal diseases, rather than due to a positive faecal occult blood test performed in the later CRC screening programme.

Third, the quality of PCCRC categorization is highly dependent on the validity of coding of dates in the DNPR and the DCR. Hence, dCRCs can be misclassified as PCCRCs if dates of colonoscopies or CRCs are coded ambiguously. However, expansion of the PCCRC definition in our sensitivity analysis did not yield findings that differed from the pattern seen on our main analysis. 
Table 3 Colonoscopies categorised as false-negative* or true-positive $\dagger$ and PCCRC 3-year rates $\ddagger$ stratified by presence of type 2 diabetes (T2D)

Colonoscopies

PCCRC

3-year

False-negative

colonoscopies*, $\mathbf{n}$

True-positive colonoscopiest,

rateł

\begin{tabular}{|c|c|c|c|c|}
\hline Patients with T2D & 250 & 2938 & 3188 & 7.90 \\
\hline \multicolumn{5}{|l|}{ Sex } \\
\hline Female & 113 & 1134 & 1247 & 9.10 \\
\hline Male & 137 & 1806 & 1943 & 7.00 \\
\hline \multicolumn{5}{|l|}{ Age at colonoscopy } \\
\hline $0-59$ & 21 & 257 & 378 & 7.60 \\
\hline $60-69$ & 73 & 834 & 907 & 8.00 \\
\hline $70+$ & 156 & 1847 & 2003 & 7.80 \\
\hline \multicolumn{5}{|l|}{ Year of colonoscopy } \\
\hline 1995-2001 & 28 & 75 & 103 & 27.20 \\
\hline 2002-2008 & 81 & 788 & 869 & 9.30 \\
\hline 2009-2015 & 141 & 2075 & 2216 & 6.40 \\
\hline Patients without T2D & 1,658 & 20594 & 22252 & 7.40 \\
\hline \multicolumn{5}{|l|}{ Sex } \\
\hline Female & 844 & 9,819 & 10663 & 7.90 \\
\hline Male & 814 & 10775 & 11589 & 7.00 \\
\hline \multicolumn{5}{|l|}{ Age at colonoscopy } \\
\hline $0-59$ & 259 & 3565 & 3824 & 6.80 \\
\hline $60-69$ & 453 & 5975 & 6428 & 7.00 \\
\hline $70+$ & 946 & 11054 & 12000 & 7.90 \\
\hline \multicolumn{5}{|l|}{ Year of colonoscopy } \\
\hline 1995-2001 & 382 & 1198 & 1580 & 24.20 \\
\hline 2002-2008 & 664 & 6508 & 7172 & 9.20 \\
\hline 2009-2015 & 612 & 12888 & 13500 & 4.50 \\
\hline
\end{tabular}

Denmark, 1995-2015.

*Colonoscopies in which a CRC was diagnosed within $>6$ to 36 months after the procedure.

†Colonoscopies in which a CRC was detected within the following 6 months.

$\ddagger$ False-negative colonoscopies/ (true-positive colonoscopies+false-negative colonoscopies) $\times 100$.

$\S$ Diagnosis of T2D recorded in the Danish National Patient Registry before or within 90 days after the first false-negative or true-positive colonoscopy and/or at least one redeemed prescription for a glucose-lowering drug recorded in the Danish National Health Service

Prescription Database before or within 90 days after the first false-negative or true-positive colonoscopy. Patients with diabetes diagnoses and prescriptions recorded before age 30 not included as these were considered to represent patients with type 1 diabetes.

TEach individual was allowed one or more colonoscopy; however, only the first false-negative and true-positive colonoscopies were included in these numbers and the calculated PCCRC 3-year rates.

$\mathrm{CRC}$, colorectal cancer; PCCRC, postcolonoscopy colorectal cancer.

Thus, such misclassification likely accounts for an insignificant source of bias.

Fourth, our identification of patients with diabetes requires consideration. Due to small numbers of patients with type 1 diabetes undergoing colonoscopy, our main focus was on patients with T2D. Thus, our results are only applicable for patients with T2D. In addition, the ICD coding of diabetes in the DNPR did not allow us to distinguish type 1 diabetes from T2D. We, therefore, considered patients with type 1 diabetes as those with relevant diagnoses and prescriptions recorded before age 30 . Our approach was based on prior research; unfortunately, no validation study exists. Furthermore, the use of prescriptions to identify patients with diabetes has its limitations as metformin is prescribed for other diseases such as polycystic ovary syndrome. Finally, our cohort of non-exposed patients might contain individuals with asymptomatic and undiagnosed T2D. Occurrence of polycystic ovary syndrome in our exposed group as well as occurrence of undiagnosed cases of T2D in our reference group could have introduced a conservative bias. 
In conclusion, we found that patients with T2D had an increased HR of PCCRC compared with patients without T2D. These findings could indicate that impaired quality of bowel preparation for colonoscopy among patients with T2D may increase the risk of overlooked precancerous polyps, thereby increasing the risk of PCCRC.

Contributors FST, HTS, LP and RE contributed to the methodology of the study. HTS, LP and RE acquired the data. FST, HTS, LP and RE directed the analyses, which were carried out by FST. FST wrote the initial draft. All authors contributed to the discussion and interpretation of the results, which determined the intellectual content of the manuscript. All authors reviewed, edited and accepted the final version for submission. FST is the guarantor of the article.

Funding FST is supported by a scholarship from Aarhus University. The study was supported by grants from the Novo Nordisk Foundation (NNF190C0058609) and the Danish Cancer Society (R247-A14719).

Disclaimer The funding sources had no role in the design and conduct of the study, nor the analysis and interpretation of the data.

Competing interests None declared.

Patient consent for publication Not applicable.

Provenance and peer review Not commissioned; externally peer reviewed.

Data availability statement № data are available.

Supplemental material This content has been supplied by the author(s). It has not been vetted by BMJ Publishing Group Limited (BMJ) and may not have been peer-reviewed. Any opinions or recommendations discussed are solely those of the author(s) and are not endorsed by BMJ. BMJ disclaims all liability and responsibility arising from any reliance placed on the content. Where the content includes any translated material, BMJ does not warrant the accuracy and reliability of the translations (including but not limited to local regulations, clinical guidelines, terminology, drug names and drug dosages), and is not responsible for any error and/or omissions arising from translation and adaptation or otherwise.

Open access This is an open access article distributed in accordance with the Creative Commons Attribution Non Commercial (CC BY-NC 4.0) license, which permits others to distribute, remix, adapt, build upon this work non-commercially, and license their derivative works on different terms, provided the original work is properly cited, appropriate credit is given, any changes made indicated, and the use is non-commercial. See: http://creativecommons.org/licenses/by-nc/4.0/.

ORCID iD

Frederikke Schønfeldt Troelsen http://orcid.org/0000-0002-5276-5959

\section{REFERENCES}

1 Rutter MD, Beintaris I, Valori R, et al. World endoscopy organization consensus statements on Post-Colonoscopy and Post-Imaging colorectal cancer. Gastroenterology 2018;155:909-25.

2 Winawer SJ, Zauber AG, Ho MN, et al. Prevention of colorectal cancer by colonoscopic polypectomy. The National Polyp study Workgroup. N Engl J Med 1993;329:1977-81.

3 Rex DK, Rahmani EY, Haseman JH, et al. Relative sensitivity of colonoscopy and barium enema for detection of colorectal cancer in clinical practice. Gastroenterology 1997:112:17-23.

4 Arain MA, Sawhney M, Sheikh S, et al. Cimp status of interval colon cancers: another piece to the puzzle. Am J Gastroenterol 2010;105:1189-95.

5 Singh $\mathrm{H}$, Nugent Z, Demers AA, et al. Rate and predictors of early/missed colorectal cancers after colonoscopy in Manitoba: a population-based study. Am J Gastroenterol 2010;105:2588-96.

6 Gorski TF, Rosen L, Riether R, et al. Colorectal cancer after surveillance colonoscopy: false-negative examination or fast growth? Dis Colon Rectum 1999;42:877-80.

7 Cooper GS, Xu F, Barnholtz Sloan JS, et al. Prevalence and predictors of interval colorectal cancers in Medicare beneficiaries. Cancer 2012;118:3044-52.

8 Stoffel EM, Erichsen R, Frøslev T, et al. Clinical and molecular characteristics of Post-Colonoscopy colorectal cancer: a populationbased study. Gastroenterology 2016;151:870-8.

9 Morris EJA, Rutter MD, Finan PJ, et al. Post-colonoscopy colorectal cancer (PCCRC) rates vary considerably depending on the method used to calculate them: a retrospective observational populationbased study of PCCRC in the English National health service. Gut 2015;64:1248-56.

10 Teixeira C, Martins C, Dantas E, et al. Interval colorectal cancer after colonoscopy. Rev Gastroenterol Mex 2019;84:284-289.

11 Adler J, Robertson DJ. Interval colorectal cancer after colonoscopy: exploring explanations and solutions. Am J Gastroenterol 2015;110:1657-64. quiz 65.

12 Stjärngrim J, Ekbom A, Hammar U, et al. Rates and characteristics of postcolonoscopy colorectal cancer in the Swedish IBD population: what are the differences from a non-IBD population? Gut 2019;68:1588-1596

13 Wang YR, Cangemi JR, Loftus EV, et al. Rate of early/missed colorectal cancers after colonoscopy in older patients with or without inflammatory bowel disease in the United States. Am J Gastroenterol 2013;108:444-9.

14 Burr NE, Derbyshire E, Taylor J, et al. Variation in post-colonoscopy colorectal cancer across colonoscopy providers in English National health service: population based cohort study. BMJ 2019;367:1609 $0-190$.

15 Pedersen L, Valori R, Bernstein I, et al. Risk of post-colonoscopy colorectal cancer in Denmark: time trends and comparison with Sweden and the English National health service. Endoscopy 2019;51:733-41.

16 Erichsen R, Baron JA, Stoffel EM, et al. Characteristics and survival of interval and sporadic colorectal cancer patients: a nationwide population-based cohort study. Am J Gastroenterol 2013;108:1332-40

17 Forsberg A, Widman L, Bottai M, et al. Postcolonoscopy colorectal cancer in Sweden from 2003 to 2012: survival, tumor characteristics, and risk factors. Clin Gastroenterol Hepatol 2020:18:2724-33.

18 Wolff JL, Starfield B, Anderson G. Prevalence, expenditures, and complications of multiple chronic conditions in the elderly. Arch Intern Med 2002;162:2269-76.

19 Saraggi D, Fassan M, Mescoli C, et al. The molecular landscape of colitis-associated carcinogenesis. Dig Liver Dis 2017;49:326-30.

20 Yılmaz Ürün Y, Üstündağ Y. Post-colonoscopy colorectal cancer rates in the Swedish IBD and non-IBD population: something missed or something faster? Turk J Gastroenterol 2019;30:860-2.

21 Miłek T, Forysiński K, Myrcha P, et al. Diabetes association of polyps and colon cancer. Pol Przegl Chir 2019;91:9-12.

22 Soltani G, Poursheikhani A, Yassi M, et al. Obesity, diabetes and the risk of colorectal adenoma and cancer. BMC Endocr Disord 2019;19:113.

23 Ahmed RL, Schmitz KH, Anderson KE, et al. The metabolic syndrome and risk of incident colorectal cancer. Cancer 2006:107:28-36.

24 González N, Prieto I, Del Puerto-Nevado L, et al. 2017 update on the relationship between diabetes and colorectal cancer: epidemiology, potential molecular mechanisms and therapeutic implications. Oncotarget 2017;8:18456-85.

25 Pollak M. Insulin and insulin-like growth factor signalling in neoplasia. Nat Rev Cancer 2008;8:915-28.

26 Koenuma M, Yamori T, Tsuruo T. Insulin and insulin-like growth factor 1 stimulate proliferation of metastatic variants of colon carcinoma 26. Jpn J Cancer Res 1989;80:51-8.

27 Björk J, Nilsson J, Hultcrantz R, et al. Growth-Regulatory effects of sensory neuropeptides, epidermal growth factor, insulin, and somatostatin on the non-transformed intestinal epithelial cell line IEC-6 and the colon cancer cell line HT 29. Scand J Gastroenterol 1993;28:879-84

28 Tran TT, Medline A, Bruce WR. Insulin promotion of colon tumors in rats. Cancer Epidemiol Biomarkers Prev 1996:5:1013-5.

$29 \mathrm{Ma}$ J, Pollak MN, Giovannucci E, et al. Prospective study of colorectal cancer risk in men and plasma levels of insulin-like growth factor (IGF)-I and IGF-binding protein-3. J Natl Cancer Inst 1999;91:620-5.

$30 \mathrm{Ma}$ J, Giovannucci E, Pollak M, et al. A prospective study of plasma C-peptide and colorectal cancer risk in men. J Natl Cancer Inst 2004;96:546-53.

31 Nguyen AV, Wu Y-Y, Lin EY. Stat3 and sphingosine-1-phosphate in inflammation-associated colorectal cancer. World J Gastroenterol 2014;20:10279-87.

32 Saeedi P, Petersohn I, Salpea P, et al. Global and regional diabetes prevalence estimates for 2019 and projections for 2030 and 2045: Results from the International Diabetes Federation Diabetes Atlas, $9^{\text {th }}$ edition. Diabetes Res Clin Pract 2019;157:107843.

33 Serper M, Gawron AJ, Smith SG, et al. Patient factors that affect quality of colonoscopy preparation. Clin Gastroenterol Hepatol 2014;12:451-7. 
34 Horváth VJ, Putz Z, Izbéki F, et al. Diabetes-Related dysfunction of the small intestine and the colon: focus on motility. Curr Diab Rep 2015; $15: 94$.

35 Anderson R, Burr NE, Valori R. Causes of Post-Colonoscopy colorectal cancers based on world endoscopy organization system of analysis. Gastroenterology 2020;158:1287-99.

36 Tollivoro TA, Jensen CD, Marks AR, et al. Index colonoscopy-related risk factors for postcolonoscopy colorectal cancers. Gastrointest Endosc 2019;89:168-76.

37 Schmidt M, Schmidt SAJ, Adelborg K, et al. The Danish health care system and epidemiological research: from health care contacts to database records. Clin Epidemiol 2019;11:563-91.

38 Pedersen CB. The Danish civil registration system. Scand J Public Health 2011;39:22-5.

39 Schmidt M, Pedersen L, Sørensen HT. The Danish civil registration system as a tool in epidemiology. Eur J Epidemiol 2014;29:541-9.

40 Schmidt M, Schmidt SAJ, Sandegaard JL, et al. The Danish national patient registry: a review of content, data quality, and research potential. Clin Epidemiol 2015;7:449-90.

41 Johannesdottir SA, Horváth-Puhó E, Ehrenstein V, et al. Existing data sources for clinical epidemiology: the Danish national database of Reimbursed prescriptions. Clin Epidemiol 2012;4:303-13.

42 Thomsen RW, Hundborg $\mathrm{HH}$, Lervang $\mathrm{H}-\mathrm{H}$, et al. Diabetes and outcome of community-acquired pneumococcal bacteremia: a 10year population-based cohort study. Diabetes Care 2004;27:70-6.

43 Schønfeldt Troelsen F, Sørensen HT, Pedersen L, et al. Risk of a post-colonoscopy colorectal cancer diagnosis in patients with inflammatory bowel disease: a population-based cohort study. Endoscopy 2021;53:1023-1033.

44 Gjerstorff ML. The Danish cancer registry. Scand J Public Health 2011;39:42-5.

45 Coviello V, Boggess M. Cumulative incidence estimation in the presence of competing risks. Stata J 2004;4:103-12.

46 Jarvandi S, Davidson NO, Schootman M. Increased risk of colorectal cancer in type 2 diabetes is independent of diet quality. PLoS One 2013;8:e74616.

47 Goto A, Noto H, Noda M, et al. Report of the Japan diabetes society/Japanese cancer association joint Committee on diabetes and cancer, second report. Cancer Sci 2016;107:369-71.

48 Tsilidis KK, Kasimis JC, Lopez DS, et al. Type 2 diabetes and cancer: umbrella review of meta-analyses of observational studies. BMJ 2014;350:g7607.

49 Dankner R, Boffetta P, Balicer RD, et al. Time-Dependent risk of cancer after a diabetes diagnosis in a cohort of 2.3 million adults. Am J Epidemiol 2016;183:1098-106.
50 Nilsen TI, Vatten LJ. Prospective study of colorectal cancer risk and physical activity, diabetes, blood glucose and BMI: exploring the hyperinsulinaemia hypothesis. Br J Cancer 2001;84:417-22.

51 de Kort S, Simons CCJM, van den Brandt PA, et al. Diabetes mellitus type 2 and subsite-specific colorectal cancer risk in men and women: results from the Netherlands cohort study on diet and cancer. Eur J Gastroenterol Hepatol 2016;28:896-903.

52 Farrar WD, Sawhney MS, Nelson DB, et al. Colorectal cancers found after a complete colonoscopy. Clin Gastroenterol Hepatol 2006;4:1259-64.

53 Froehlich F, Wietlisbach V, Gonvers J-J, et al. Impact of colonic cleansing on quality and diagnostic yield of colonoscopy: the European panel of appropriateness of gastrointestinal endoscopy European multicenter study. Gastrointest Endosc 2005;61:378-84.

54 Golay A, Chen YD, Reaven GM. Effect of differences in glucose tolerance on insulin's ability to regulate carbohydrate and free fatty acid metabolism in obese individuals. J Clin Endocrinol Metab 1986;62:1081-8

55 Tabák AG, Jokela M, Akbaraly TN, et al. Trajectories of glycaemia, insulin sensitivity, and insulin secretion before diagnosis of type 2 diabetes: an analysis from the Whitehall II study. Lancet 2009;373:2215-21.

56 Mitrakou A, Kelley D, Mokan M, et al. Role of reduced suppression of glucose production and diminished early insulin release in impaired glucose tolerance. N Engl J Med 1992;326:22-9.

57 Dulai PS, Sandborn WJ, Gupta S. Colorectal cancer and dysplasia in inflammatory bowel disease: a review of disease epidemiology, pathophysiology, and management. Cancer Prev Res 2016;9:887-94

58 Harpaz N, Ward SC, Mescoli C, et al. Precancerous lesions in inflammatory bowel disease. Best Pract Res Clin Gastroenterol 2013;27:257-67.

59 Scarpa M, Castagliuolo I, Castoro C, et al. Inflammatory colonic carcinogenesis: a review on pathogenesis and immunosurveillance mechanisms in ulcerative colitis. World J Gastroenterol 2014;20:6774-85.

60 Olén O, Erichsen R, Sachs MC, et al. Colorectal cancer in ulcerative colitis: a Scandinavian population-based cohort study. Lancet 2020;395:123-31.

61 Olén O, Erichsen R, Sachs MC. Colorectal cancer in Crohn's disease: a Scandinavian population-based cohort study. Lancet Gastroenterol Hepatol 2020;S2468-1253:30005-4.

62 Erichsen R, Baron JA, Hamilton-Dutoit SJ, et al. Increased risk of colorectal cancer development among patients with serrated polyps. Gastroenterology 2016;150:895-902.

63 Njor SH, Friis-Hansen L, Andersen B, et al. Three years of colorectal cancer screening in Denmark. Cancer Epidemiol 2018;57:39-44. 